\section{ECONOMICS}

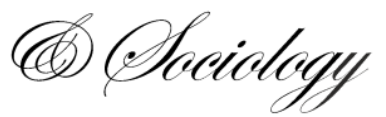

Smeureanu, I., \& Diab, B. (2020). Investigating top management preparedness for leading IT governance during the coronavirus crisis. Economics and Sociology, 13(4), 97-106. doi:10.14254/2071-789X.2020/13-4/6

\title{
INVESTIGATING TOP MANAGEMENT PREPAREDNESS FOR LEADING IT GOVERNANCE DURING THE CORONAVIRUS CRISIS
}

\author{
Ion Smeureanu \\ The Bucharest University of \\ Economic Studies, Bucharest, \\ Romania \\ E-mail: ion.smeureanu@,csie.ase.ro

\section{Bassel Diab} \\ The Bucharest University of \\ Economic Studies, Bucharest, \\ Romania \\ E-mail: basseljdiab@gmail.com
}

Received: February, 2020

1st Revision: September, 2020

Accepted: December, 2020

DOI: $10.14254 / 2071-$

789X.2020/13-4/6

JEL Classification: C12,
M15, D83

\begin{abstract}
This paper aims to examine the extent to which top management strategically thinks so that their organizations are completely ready to carry on being wellfunctioning in all business aspects during the periods of unpredictability or crisis. We mainly focus on testing the impact of a set of mechanisms, representing some preparedness measures, on the ITG maturity of the surveyed organizations in Lebanon. The empirical findings of the conducted survey reveal that the major enablers of effective ITG leadership under crisis are "Periodic communication of ITG mechanisms" and "Tested crisis communication plan" while five other factors have moderate influence and one factor has little influence.
\end{abstract}

Keywords: IT governance, crisis management, communication approaches, top management inclusion in IT.

\section{Introduction}

The business world has witnessed a long list of crises in the several previous years. For instance, the fail of Facebook PR in 2016, the arrest of ex-Nissan's board chairman in 2018, the arrest of Huawei's CFO in 2018 and many other crises have turned crisis management and corporate governance in particular into one of the hot topics for research. During the periods of stability, executives are required to oversee the overall operations of their organizations and to address the most vital business needs. Smeureanu \& Diab state that "CEOs and CIOs could witness moral hazard throughout their collaboration...Thus, CEOs are substantially invited to proceed with business governance of IT strategies and projects so as to prevent immoral attitude from the side of CIOs or other IT executives, and to push them to converge on the company's overall common interest" (BASIQ, 2020). On the other side, in times of crisis, the invasion of IT into the world of business urges McNulty \& Marcus (2020) to argue that executives have not only to manage but also to lead people "to the best possible eventual outcome over this arc of time", taking into account a crisis can make or break companies which 
necessitates a response at the executive -level. The British Standards Institute (BSI)'s European Guidance on Crisis Management has best defined a crisis as "an unprecedented or extraordinary event or situation that threatens an organization and requires a strategic, adaptive, and timely response in order to preserve its viability and integrity".

\section{Motivation for this Study}

Executives and leaders must be attentive since a crisis could occur any time so that they have to foresee what kinds of disruptions or changes might face their organizations. They have to set and test emergency plans to deal with uncertain losses their businesses might experience. Otherwise, if leaders deny the necessity to anticipate potential critical difficulties, then organizations could probably witness what Kanter describes as "When crisis looms, losses can spiral out of control, turning into self-reinforcing losing streaks, where everything gets worse before there's a chance to catch a positive wave" (HBR, 2020). Also, in their paper titled "Investigating the impact of organizational culture on information technology governance", Smeureanu \& Diab (2020) surveyed a sample of large organizations operating in Lebanon and found that the main enabling mechanisms of governance in IT are "Communication Approaches" and "Top Management inclusion in IT". This fact motivates the authors, especially under the coronavirus pandemic, to explore the readiness and the willingness of the same surveyed organizations to confronting similar crisis of any nature (e.g., financial, natural, health one) mainly regarding IT governance. Accordingly, the research questions are: Are organizations really prepared to keep IT governance smoothly running during a crisis? What are the major enablers of leading IT governance during crisis?

Following the review of literature available on IT governance during the crises in Lebanon, a very few articles or postings on crisis management can be found, such as Jallat \& Shultz (2011) and Salameh (2020). This shortage of research studies has stimulated the researchers to explore the urgency of clear crisis management planning, keeping in mind the succession of crises in Lebanese business community (e.g., banking crisis, monetary crisis, and economic recession). Therefore, we aspire to provide top management with an empirical study deepening their knowledge about the factors which have the most powerful effect on the maturity and performance of IT governance, while large organizations in Lebanon are living under the unprecedented circumstances due to the ongoing coronavirus pandemic.

\section{Literature review}

Readers should recognize the theoretical grounds which form the basis of our investigation. So it is necessary to divide this section into two sub-sections. First sub-section discusses the process of crisis management and the role played by IT. The second one constitutes a review of studies tackling the importance of strategic planning by top managements regarding any risks that might arise and consequently disturb organizational stability, where IT governance is placed on top of the list of concerns.

\section{Crisis Management Process}

Any organization regardless of its size might be subject to different types of threats as the death of its CEO or a terrorist attack. Such unpredictable events could dramatically force organizations to seriously modify the way they run business operations. Therefore, top managements are required to develop a "business continuity plan" in order to alleviate any unforeseen outcomes. Hayes suggests that "the process of having a continuity plan in place in the event of a crisis is known as crisis management" (2019). In 2020, Johnson \& Suskewicz insist that managing crisis requires visionary leaders who "cannot predict what is coming with perfect certainty... but can create a plan to live into it and then set it into motion". 20 years 
ago, the dotcom crash chocked Apple's computer business, but Steve Jobs envisioned and started to plan for the iPod and iPhone. Moreover, the Chinese experience during coronavirus pandemic leads Reeves et al. (2020) to deduce that "Considering the time it takes to formulate, disseminate, and apply new policies in large companies, recovery planning needs to start while you 're still reacting to the crisis".

Many researchers have studied the contribution of IT and IS to an effective crisis management. Here, it is worth mentioning that the global IT spending has an average of 3.8 trillion USD per year. For instance, Yasushi claims that "Information communication technology (ICT) has been recognized as an indispensable instrument, not only to assist onsite activities of professional emergency responders, but also to support collaborative actions of a wide-range of stakeholders for effective preparedness" (2015). Nasr \& Zhen examine the effectiveness of ICTs in the security sector institutions during the ongoing war crisis in Yemen; they find limited use of ICTs in SSI which instead greatly rely on executives' experience to lead crisis (2017). Also, Tim et al. (2017) say that social media boosts situational awareness and two-way communication while witnessing crisis. Furthermore, Raki \& Abderraouf (2018) address the role of modern technology in managing crisis through "shortening reactions times, improving consistency of message, providing relevant and redundant information for stakeholders, and by providing back-channels between organizations and its different stakeholder". On the other side, the severe economic downturn caused by coronavirus crisis is forcing Chief Information Officers (CIOs) to respond according to a totally different vision while prioritizing investments in IT "on operations that keep the business running" (Lovelock, 2020).

\section{ITG during Crisis}

In last decades, many researchers have been attempting to explore the necessity of planning in advance for safeguarding the survival of organizations during crisis or situations involving corporate misconduct or particular governance issues. The Global Center for Corporate Governance of Deloitte defines crisis plans as "They are not a step-by-step guide for what to do next, but a set of rules within a framework in which good decisions can be made, implemented and communicated".

A big number of studies have addressed crisis management and the role of information technology as a buffer supporting organizations' managements to maintain balance and not to lose control while steering their organizations till going out of crisis. Salameh (2019) writes about the necessary steps to survive crises and even to thrive afterward. He recommends that "A well planned, well communicated and well executed crisis management framework will validate that your company has solid foundations in place to address most of the challenges and risk factors that may develop in the future". The coronavirus stimulates Taliawi \& Wal (2020) to extract the major lessons in crisis governance; they find that effective communication is a key pillar of governance. They describe how communication under high levels of stress and tensity could be traumatic. Also, they argue that using terms which are easy to understand, "being transparent and accurate in relaying information... and expressing a degree of empathy in communicating policies can go a long way in ensuring effective crisis communications". Information and Communication Technologies (ICTs) are critical for timely communication boosting managerial decision-making (Mehta, 2019). Mehta explains that "ICTs play a significant role in mitigation, preparedness, response, and rehabilitation by facilitating the flow of vital information in a timely manner". Pierri \& Timmer (2020) find that commercial banks which were alert and therefore adopted high technologies before the Global Crisis were more resilient in front of the financial crisis particularly. They also conclude that IT adoption had a significant impact on its financial stability. 
Nevertheless, scholars are not considering yet the issue of directing business governance of IT strategies within crisis as an urgent topic. They are not focusing as well on identifying the correlation between proper and efficacious preparation and the capability of top managements to lead IT governance during stages of uncertainty. In this paper, the researchers aim to contribute to bridging the gap found in this area of research by focusing on testing the influence of managements" preparations on the maturity of IT governance during crisis.

\section{Methodological approach}

This article tries to discover whether top managements of large organizations are truly prepared to secure the continuity of ITG practice without disruption whenever a specific corporate crisis or a national crisis occurs. It focuses on identifying the impact of managements' preparedness degree for crisis on ITG maturity within times of insecurity. In addition, the research model of our study (Fig. no. 1) is developed based on the pertinent literature and managed following the questionnaire technique.

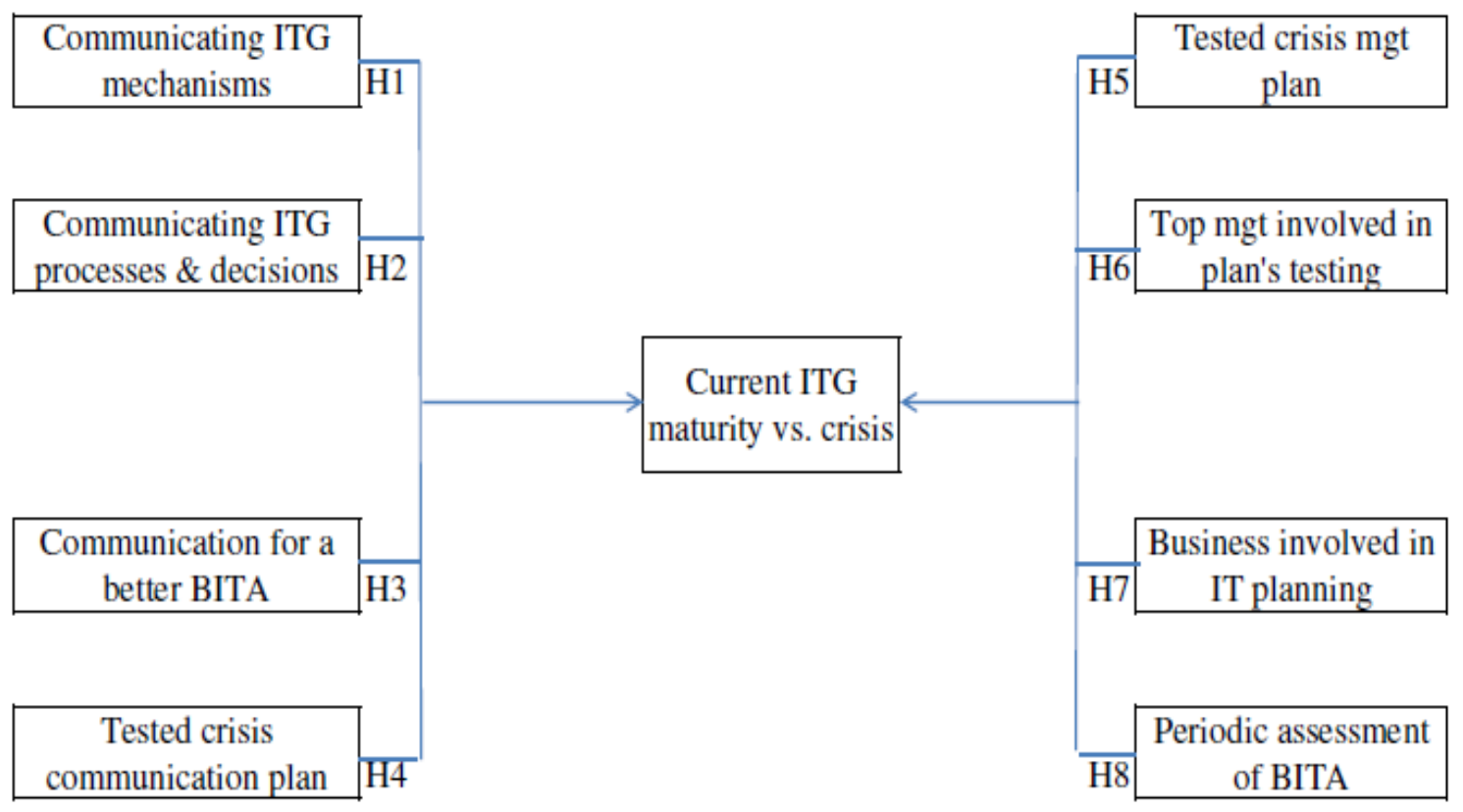

Figure 1. The Research Model of preparing for ITG continuity during crisis

The relevant hypotheses which are subject to empirical test are presented below accompanied with a short explanation of the 2 sets of independent variables included in the research model. One set contains 4 preparedness measures directly associated with organizational communication and a second set includes 4 other measures directly linked to the inclusion of top managements in IT, in order to examine its effect on the ITG level of organizations during crisis.

\section{Communication approaches:}

Smeureanu \& Diab (2020) state that "Organizational communication is a leading enabler of a healthy environment of internal control. Communication is supposed to support the satisfaction of the wealth/value maximization goal of owners, controlled by ITG”. Thus,

H1 is: Periodic communication of ITG mechanisms positively influences ITG maturity during crisis. 
$\mathrm{H} 2$ is: Periodic communication of ITG decisions positively influences ITG maturity during crisis.

H3 is: Periodic communication to assess BITA positively influences ITG maturity during crisis.

H4 is: Tested crisis communication plan positively influences ITG maturity during crisis.

Top management inclusion in IT:

Top management refers to executives like CEO or others reporting directly to the CEO. Schwartz argues that "management support and setting the example" are the most influential mechanisms that leaders should adopt" (Smeureanu \& Diab, 2020). Smeureanu \& Diab claim that "Similar to communication systems, management inclusion in IT boosts facilitates the wealth/value maximization goal pursued by owners". Thus,

H5 is: Tested plan for delegating authorities positively influences ITG maturity during crisis.

H6 is: Top management involvement in plans testing positively influences ITG maturity during crisis. crisis.

H7 is: Business involvement in IT planning positively influences ITG maturity during

H8 is: Periodic assessment of BITA positively influences ITG maturity during crisis.

\section{Conducting research and results}

The authors conduct a questionnaire which includes a set of self-developed questions following a 6-point Likert scale. Respondents are executives (e.g. CEO, CIO) in large organizations of various industries running business in Lebanon. The dependent variable is the ITG maturity during the coronavirus pandemic crisis and the independent variables are: communicating ITG mechanisms, communicating ITG processes \& decisions, communicating IT benefits/risks, communication for a better BITA, existence of a crisis communication plan, existence of a crisis management plan, top management involved in plan's testing, strategic discussions with IT, ITG plan for crisis and periodic assessment of BITA.

The questions included in the adopted questionnaire are as follow:

Communication approaches:

1) Does top management have periodic communication with employees to measure their awareness of the existence of ITG mechanisms?

2) Does top management regularly review the organizational communication mechanisms/systems to ensure employees are completely aware of ITG decisions and processes?

3) Does top management/BOD have periodic communication with stakeholders to keep them completely aware of the possible business benefits or risks associated with the use of IT?

4) Do top IT executives use common business language to translate technological benefits and risks into business terms for an enhanced strategic business-IT alignment?

5) Does top management/BOD have a tested and validated plan to communicate with stakeholders honestly and timely during crisis? (i.e. frequency, mode...)

Top management inclusion in IT:

1) Does top management/BOD have a tested crisis management plan?

2) Is top management/BOD directly involved in exercises performed to test that plan?

3) What is the extent to which top management/BOD has been pushing IT executives into strategic discussions in anticipation of any possible crisis?

4) Does top management/BOD plan ahead to safeguard ITG running during crisis? 
5) Does top management/BOD assess periodically the maturity of BITA?

It is worth reminding that General Managers, CEOs, CIOs and internal audit managers represent $46 \%, 24 \%, 18 \%$ and $12 \%$ of respondents respectively. The mean managerial experience is 8.9 years where respondents are familiar with IT governance scoring 5 on a 6point scale as an average. To test the goodness-of-fit of the model, we did a Chi-square $(\chi 2)$ test and concluded that 208.964> 30.6 with 15 degree of freedom at a critical value of 0.01 . This means that the model greatly fits our data.

\subsection{Findings and interpretations}

An online questionnaire has been sent to the same surveyed 76 executives of large enterprises of the authors' last paper titled "Investigating the impact of organizational culture on information technology governance". We calculated the Cronbach's Alpha to test the reliability of our model as well as its constructs. Cronbach's Alpha of the model is $0.875>0.70$ which implies that it is reliable and valid.

\section{Correlation Analysis}

Correlation analysis was used by the authors in order to test the proposed hypotheses already described in the research model section. Variables were tested as either accepted or rejected using SPSS.

\section{Hypothesis 1}

The correlations table shows a strong and positive relationship between periodic communication of ITG mechanisms and ITG maturity during crisis. However, the sig value in ANOVA table is less than 0.01 which indicates that the model is statistically important to be used to forecasting reliable results. Therefore, Hypothesis 1 "Periodic communication of ITG mechanisms positively influences ITG maturity during crisis" can be accepted.

\section{Hypothesis 2}

The correlations table shows a weak relationship between periodic communication of ITG decisions and ITG maturity during crisis.Also, the sig value in ANOVA table is greater than 0.01 which indicates that the model is not statistically important to be used to forecasting reliable results. Therefore, Hypothesis 2 "Periodic communication of ITG decisions positively influences ITG maturity during crisis" can be rejected.

Hypothesis 3

The correlations table shows a strong and positive relationship between periodic communication to assess BITA and ITG maturity during crisis. However, the sig value in ANOVA table is less than 0.01 which indicates that the model is statistically important to be used to forecasting reliable results. Therefore, Hypothesis 3 "Periodic communication to assess BITA positively influences ITG maturity during crisis"' can be accepted.

\section{Hypothesis 4}

The correlations table shows a strong and positive relationship between tested crisis communication plan and ITG maturity during crisis and ITG maturity during crisis. However, the sig value in ANOVA table is less than 0.01 which indicates that the model is statistically important to be used to forecasting reliable results.Therefore, Hypothesis 4 "Tested crisis communication plan positively influences ITG maturity during crisis" can be accepted.

Hypothesis 5

The correlations table shows a strong and positive relationship between tested plan for delegating authorities and ITG maturity during crisis. However, the sig value in ANOVA table is less than 0.01 which indicates that the model is statistically important to be used to forecasting reliable results. Therefore, Hypothesis 5 "Tested plan for delegating authorities positively influences ITG maturity during crisis" can be accepted. 


\section{Hypothesis 6}

The correlations table shows a strong and positive relationship between top management involvement in plans testing and ITG maturity during crisis. However, the sig value in ANOVA table is less than 0.01 which indicates that the model is statistically important to be used to forecasting reliable results. Therefore, Hypothesis 6 "Top management involvement in plans' testing positively influences ITG maturity during crisis" can be accepted.

\section{Hypothesis 7}

The correlations table shows a strong and positive relationship between business involvement in IT planningand ITG maturity during crisis. However, the sig value in ANOVA table is less than 0.01 which indicates that the model is statistically important to be used to forecasting reliable results. Therefore, Hypothesis 7 "Business involvement in IT planning positively influences ITG maturity during crisis" can be accepted.

Hypothesis 8

The correlations table shows a strong and positive relationship between periodic assessment of BITA and ITG maturity during crisis. However, the sig value in ANOVA table is less than 0.01 which indicates that the model is statistically important to be used to forecasting reliable results. Therefore, Hypothesis 8 "Periodic assessment of BITA positively influences ITG maturity during crisis" can be accepted.

Summary of hypotheses tests and results are displayed in Table 1.

Table 1. Hypotheses tests and outputs

\begin{tabular}{|c|c|c|c|c|c|c|}
\hline Independent & & Dependent Variables & Sign of & Pearson & Signifi & Result \\
\hline Variable & & & $\begin{array}{l}\text { Hypot } \\
\text { hesis }\end{array}$ & Coef. & cance & \\
\hline \multirow[t]{8}{*}{$\begin{array}{l}\text { ITG maturity } \\
\text { during crisis }\end{array}$} & Hl & $\begin{array}{l}\text { Periodic communication } \\
\text { of ITG mechanisms }\end{array}$ & + & $0.883^{* \star}$ & 0.000 & Accepted \\
\hline & H2 & $\begin{array}{l}\text { Periodic communication } \\
\text { of ITG decisions }\end{array}$ & + & $0.235^{*}$ & 0.041 & Rejected \\
\hline & H3 & $\begin{array}{l}\text { Periodic communication to } \\
\text { assess BITA }\end{array}$ & + & $0.422 * *$ & 0.000 & Accepted \\
\hline & H4 & $\begin{array}{l}\text { Tested crisis communication } \\
\text { plan }\end{array}$ & + & $0.970^{* *}$ & 0.000 & Accepted \\
\hline & H5 & $\begin{array}{l}\text { Tested plan for delegating } \\
\text { authorities }\end{array}$ & + & $0.395^{* *}$ & 0.000 & Accepted \\
\hline & H6 & $\begin{array}{l}\text { Top mgt's involvement in } \\
\text { plans' testing }\end{array}$ & + & $0.351 * *$ & 0.002 & Accepted \\
\hline & H7 & $\begin{array}{l}\text { Business involvement in IT } \\
\text { planning }\end{array}$ & + & $0.348^{* *}$ & 0.002 & Accepted \\
\hline & H8 & Periodic assessment of BITA & + & $0.368 * *$ & 0.001 & Accepted \\
\hline
\end{tabular}

Starting from the correlation coefficient results, the authors bootstrapped the actual data collected till having 1000 respondents and thereafter analyzed these data in SPSS using Neural Networks, Multilayer Perceptron, as a modeling tool aiming to minimize error and ensure accurate predictions for a better decision making. ITG maturity is the dependent variable and 
the covariates are periodic communication of ITG mechanisms, periodic communication to assess BITA, tested crisis communication plan and tested plan for delegating authorities since they have the highest Pearson coefficient. Results are illustrated in Fig. no. 2 and Fig. no. 3.

\begin{tabular}{l|r|r}
\multicolumn{2}{c}{ Independent Variable Importance } \\
& Importance & $\begin{array}{c}\text { Normalized } \\
\text { Importance }\end{array}$ \\
\hline CommlTGMech & .241 & $45.5 \%$ \\
\hline CommtoAssessBITA & .124 & $23.3 \%$ \\
\hline CrisisCommPlan & .530 & $100.0 \%$ \\
\hline PlanAuthDeleg & .105 & $19.7 \%$ \\
\hline
\end{tabular}

Figure 2. The Independent Variable Importance influencing ITG maturity

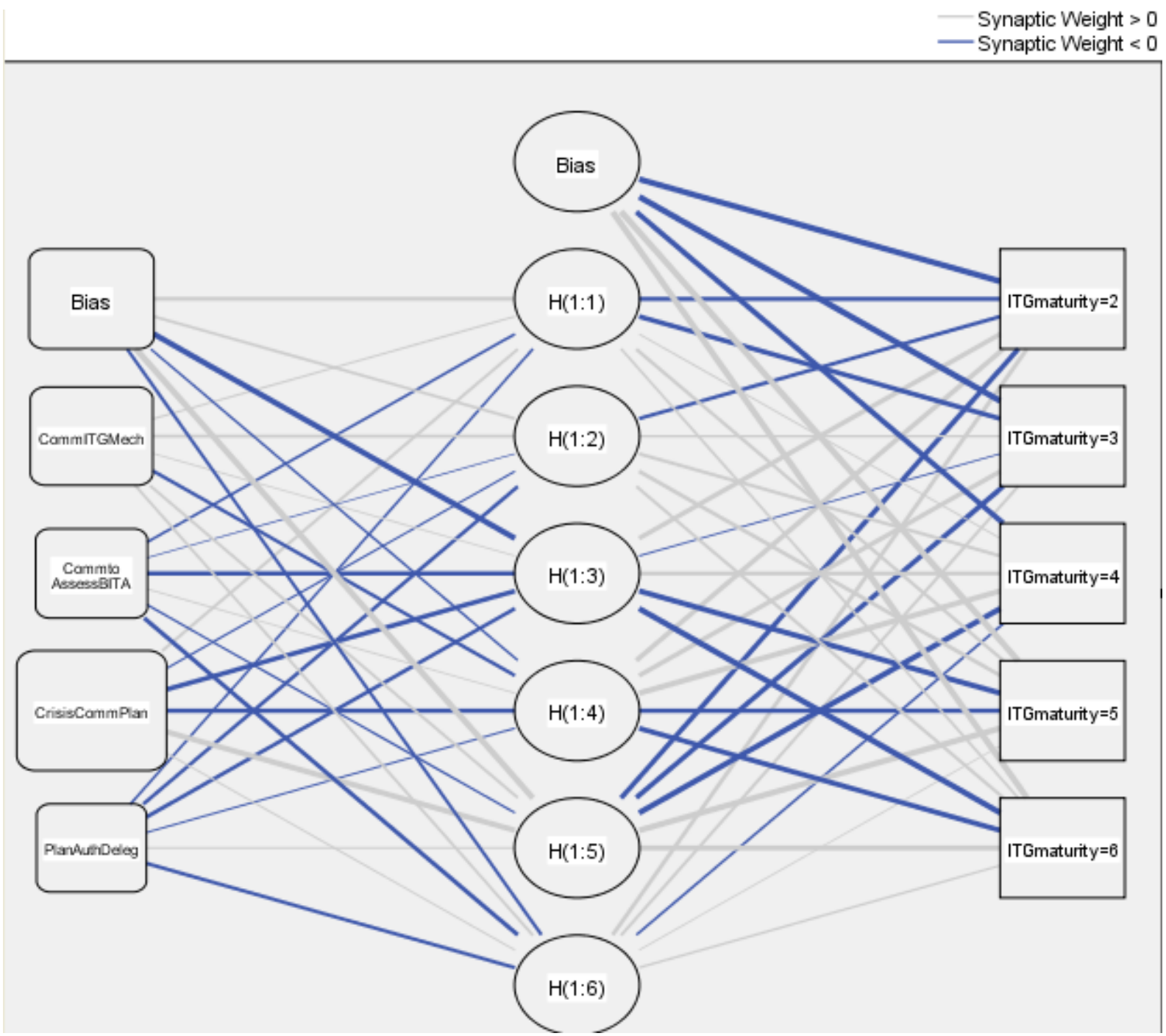

Figure 3. The Neural Network of ITG maturity

The obtained neural network links tested crisis communication plan, through $\mathrm{H}(1: 3)$, to ITG maturity $=6$. This plan has normalized importance $100 \%$, then communication of ITG mechanisms $45.5 \%$, communication to assess BITA $23.3 \%$ and finally tested plan for delegating authorities $19.7 \%$. These findings are matched with the ranking of independent variables based on their correlation's strength with ITG maturity during crisis. 


\section{Conclusion}

This research seeks to test the impact of a set of 8 factors or mechanisms on the ITG maturity of surveyed organizations currently operating midst unusual conditions caused by coronavirus.Respondents occupy senior managerial positions since they are CEOs, CIOs, GMs and internal audit managers. Findings conclude that mechanisms fallen under the umbrella of "Communication Approaches" enjoy stronger influence on the maturity of ITG in these organizations than those of "Top management inclusion in IT". The highest impact factors are "Periodic communication of ITG mechanisms" and "Tested crisis communication plan". Nevertheless, periodic communication of ITG decisions could not be empirically supported.

This article should drive the attention of executives to the significance of continuous building and promotion of rigid pillars to guarantee the continuity of their businesses. It should add to the area of research on IT governance and crisis management in Lebanon as well. Moreover, the modest mean of ITG maturity of surveyed organizations (4.7/6.0) during the actual crisis should alert top managements to adopt substantial initiatives, including those tested in our study.

Over and above, our study should open the door for other scholars to conduct additional studies like testing the same mechanisms in different context (e.g. organizationsin a specific industry or SMEs) or to find out positive impact of other factors on ITG performance.

On the other hand, our research model has been tested subjectively based on the perceptions of respondents; nonetheless, this should trigger the necessity of discovering objective measures so as to increase the reliability of findings.

\section{Acknowledgement}

This paper has been carried out under a $\mathrm{PhD}$ program at the Economic Informatics Doctoral School of The Bucharest University of Economic Studies (ASE), Romania.

\section{References}

British Standards Institution. (2014). BS11200:2014 Crisis Management - Guidance and Good Practice.

Deloitte Global Center for Corporate Governance. (2019). https://www2.deloitte.com/content/dam/Deloitte/uk/Documents/risk/deloitte-uk-riskglobal-on-the-boards-agenda-crisis-management.pdf

Hayes, A. (2019). Crisis Management. https://www.investopedia.com/terms/c/crisismanagement.asp

Yasushi, S. (2015). ICT-supported collaborative decision processes in extreme events: a comparative study. https://ethos.bl.uk/OrderDetails.do?uin=uk.bl.ethos.644526.

Johnson, M. W., \& Suskewicz, J. (2020). Leaders, do you have a clear vision for the post-crisis future? https://hbr.org/2020/04/leaders-do-you-have-a-clear-vision-for-the-post-crisisfuture

Kanter, R. M. (2020). Leading Your Team past the Peak of a Crisis. https://hbr.org/2020/04/leading-your-team-past-the-peak-of-a-crisis

McNulty, E. J., \& Marcus, L. (2020). Are you leading through the crisis... or Managing the response? https://hbr.org/2020/03/are-you-leading-through-the-crisis-or-managing-theresponse

Mehta, R. (2019). How can ICT help in disaster preparedness and response? https://www.devdiscourse.com/article/technology/597329-how-can-ict-help-in-disasterpreparedness-and-response 
Nasr, F., \& Zhen, T. (2017). International Journal of u- and e-Service, Science and Technology, 10(3), 67-82. http://dx.doi.org/10.14257/ijunesst.2017.10.3.07

Pierri, N., \& Timmer, Y. (2020). Tech in Fin before FinTech: The importance of technology in banking during a crisis. VOX, CEPR Policy Portal. https://voxeu.org/article/importancetechnology-banking-during-crisis

Raki, N., \& Abderraouf, G. (2018). Role of Communication and technology in crisis management. European Journal of Formal Sciences and Engineering, doi:10.26417/ejfe.v1i2.p39-44

Reeves, M., Fæste, L., Chen, C., Carlsson-Szlezak, P., \& Whitaker, K. (2020). How Chinese companies have responded to coronavirus. https://hbr.org/2020/03/how-chinesecompanies-have-responded-to-coronavirus

Salameh, C. (2019). Crisis Management: 10 Simple Steps to Survive the Crisis \& Thrive Afterward. entrepreneurs/ https://berytech.org/crisis-management-10-simple-steps-for-all-

Smeureanu, I. \& Diab, B., 2020. Investigating the impact of organizational culture on information technology governance. BASIQ International Conference 2020.

Taliawi, O. G., \& Wal, Z. (2020). Three lessons in crisis governance for the age of coronavirus. https://www.weforum.org/agenda/2020/04/a-guide-to-crisis-governance-in-the-age-ofcoronavirus/

Tim, Y., Pan, S. L., Ractham, P., \& Kaewkitipong, L. (2017). Digitally enabled disaster response: the emergence of social media as boundary objects in a flooding disaster. Information Systems Journal, 27(2), 197-232. 